Supporting Information

\title{
A pH-Sensitive Ligand for Luminescent Quantum Dots
}

\section{Massimiliano Tomasulo, Ibrahim Yildiz, Sireesha L. Kaanumalle and Françisco M. Raymo*}

Center for Supramolecular Science, Department of Chemistry, University of Miami

1301 Memorial Drive, Coral Gables, Florida, 33146-0431

E-Mail: fraymo@miami.edu

- Absorption Spectra of CdSe-ZnS Core-Shell Quantum Dots..

• Emission Spectra of CdSe-ZnS Core-Shell Quantum Dots ..........................................................S3 

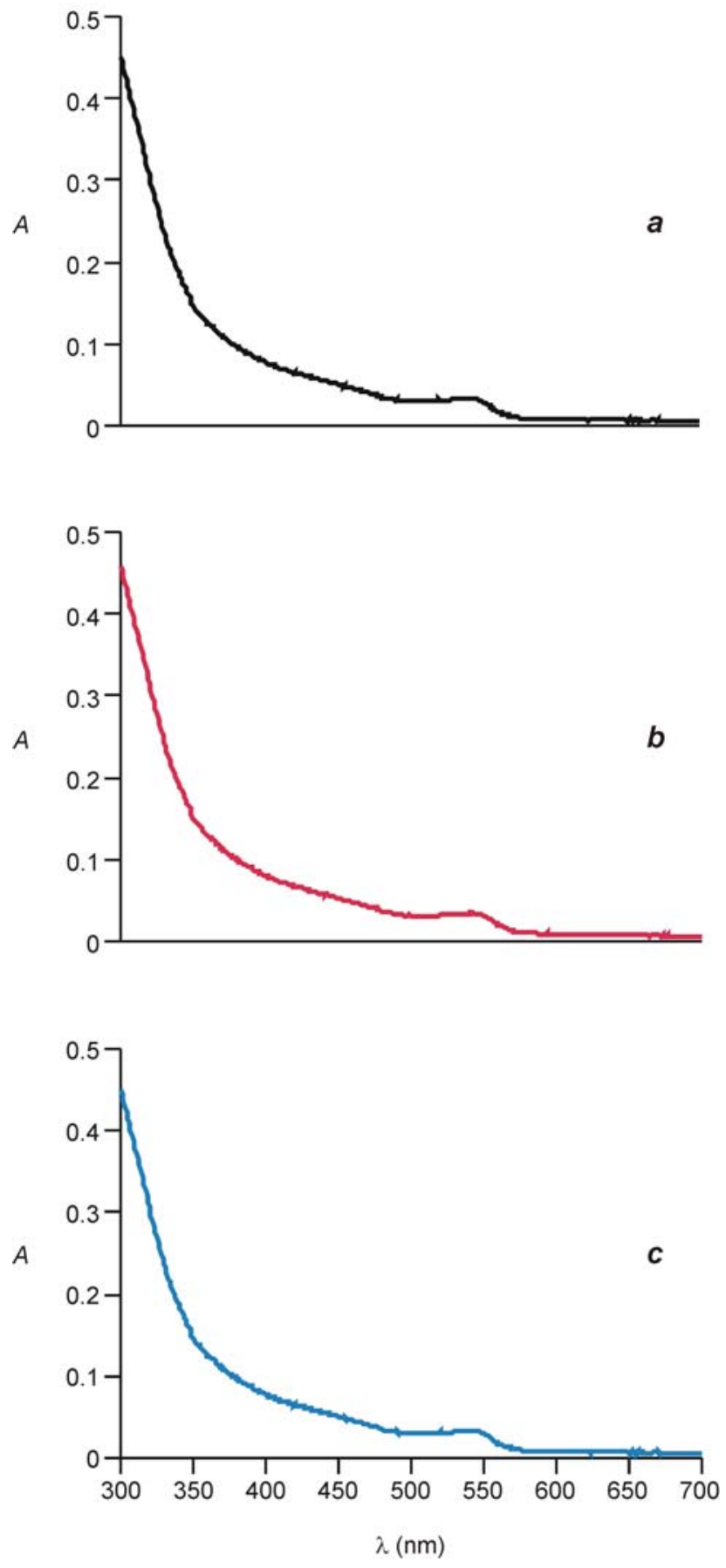

Figure S1. Absorption spectra $\left(0.7 \mu \mathrm{M}, \mathrm{CHCl}_{3}, 20^{\circ} \mathrm{C}\right)$ of $\mathrm{CdSe}-\mathrm{ZnS}$ core-shell quantum dots before (a) and after the addition of either $\mathrm{Bu}_{4} \mathrm{NOH}(\boldsymbol{b}, 4.8 \mathrm{mM})$ or $\mathrm{CF}_{3} \mathrm{CO}_{2} \mathrm{H}(\boldsymbol{c}, 4.8 \mathrm{mM})$. 

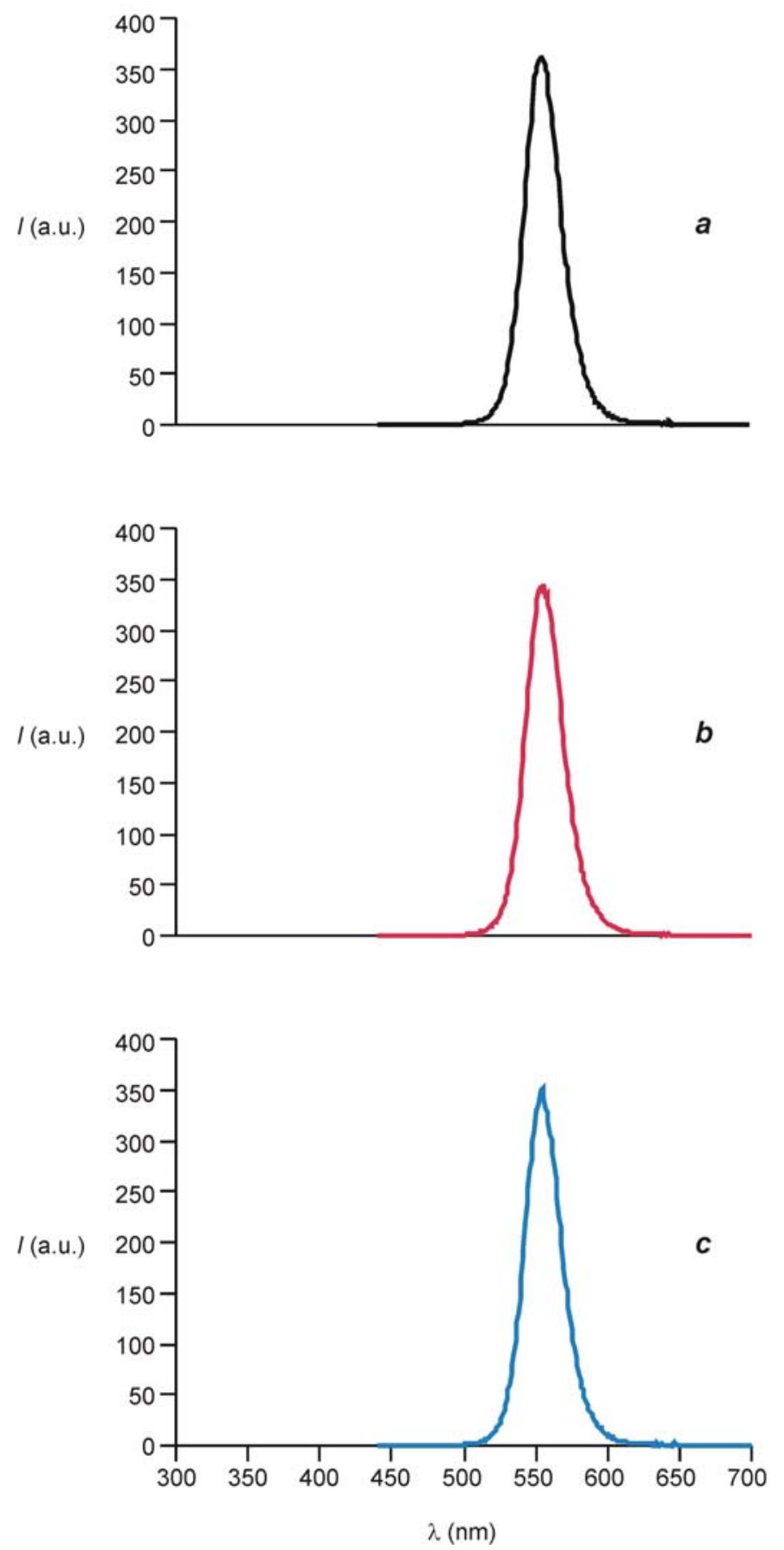

Figure S2. Emission spectra $\left(0.7 \mu \mathrm{M}, \mathrm{CHCl}_{3}, 20^{\circ} \mathrm{C}, \lambda_{\mathrm{Ex}}=375 \mathrm{~nm}\right)$ of CdSe-ZnS core-shell quantum dots before (a) and after the addition of either $\mathrm{Bu}_{4} \mathrm{NOH}(\boldsymbol{b}, 0.7 \mathrm{mM})$ or $\mathrm{CF}_{3} \mathrm{CO}_{2} \mathrm{H}(\boldsymbol{c}, 2.2 \mathrm{mM})$. 